\title{
Coryphaeuses of Present and Future
}

DOI: $10.1134 / \mathrm{S} 1061934811080181$

Among Russian analysts, there are many outstanding researchers whose contributions to science are well recognized and highly appreciated [1]. These researchers, of course, are quite different; they differ in their backgrounds, fates and fortunes, and scientific fields; among them, we can hardly find people with similar mentality or temperament. However, most of these people are distinguished by their love for science, enthusiasm, erudition, energy, initiative, diligence, sense of responsibility, often self-forgetfulness, sometimes certain aloofness, and disregard for generally accepted facts.

And how do our young colleagues look against the background of these people?

They are not only different, which is quite natural, but they are entirely different; the next generations always seem different. I suppose that young researchers are more pragmatic; they are not ideologically driven; many of them have good knowledge of foreign languages and actively use up-to-date information technologies. Of course, these are not the most important features. In the main, our young colleagues in my opinion are highly competitive against those veterans which we are ready to propose to them as an example. In any case, I hope, they will not be inferior to the older researchers in the future.
Therefore, we should actively attract young researchers to the execution of large scientific projects, try to make them heads or at least managers, and invite them to different councils, committees, commissions, editorial boards, etc. Independence and responsibility are important requirements not only for the development of a researcher in itself but also for productive scientific work. Of course, this is if he or she has talent, interest in work, extensive knowledge, diligence, etc.

Meanwhile, the majority of leading positions in the Academy of Sciences and at many universities are occupied by deserving but usually not young researchers, and the situation is changing, unfortunately, very slowly.

\section{REFERENCES}

1. Kto est' kto $v$ rossiiskoi analiticheskoi khimii. Doktora nauk (Who Is Who in Russian Analytical Chemistry: Doctors of Sciences), Zolotov, Yu.A. and Shirokova, V.I., Eds., Moscow: LKI, 2010/2011.

Yu. A. Zolotov 